\title{
A MODULE FOR TEACHING RISK MANAGEMENT
}

\author{
K. Godri-Politt and G.W. Norval \\ Department of Chemical Engineering and Applied Chemistry \\ University of Toronto \\ 200 College St. \\ Toronto, Ontario, M5S 3E5 \\ Graeme.norval@utoronto.ca
}

\begin{abstract}
The key to a successful engineering project is the early identification of hazards, followed by designing the process in such a way as to remove the hazard, or to develop means to mitigate the risk. A Hazard is an inherent property of a substance or device which can cause harm to people, property, the environment, or to a business (loss of reputation). Any one hazard can cause a loss through a number of hazardous events. Each event has a specific loss quantity and frequency. Risk is the product of the consequence and the frequency/probability of the hazardous event.
\end{abstract}

A learning module, that introduces the concepts of hazard and risk, has been developed, which is targeted at upper year engineering students. The module has examples from various disciplines and leads through the concepts of hazard identification and hazard reduction. Risk quantification is introduced, as are several techniques for risk quantification. Finally, the management of risk, including the management of residual risk

The module was provided to a class of $3^{\text {rd }}$ year chemical engineering students, to supplement an existing course in which inherently safer design techniques are taught through use of case studies and a design project. Student feedback will be presented. The module will be available for use in fall of 2014.

Keywords: Health and Safety; Risk Assessment; Risk Management

\section{INTRODUCTION}

Engineering and business decision-making is all about risk and risk management. People make risk-based decision every day, and usually without thinking about them. The problem is that in the absence of a formal decision making process - unexpected incidents can and do occur, with unintended consequence.

Risk appears in two of the Graduate Attributes: Design and Economics and Project Management. [1] Risk management begins with an understanding of hazards and risk.

A hazard is defined as a chemical or physical condition that has the potential for causing damage to people, property, or the environment. [2] The definition is deceptively simple. It includes the chemical reactivity hazards as well as those of elevated pressures. High voltage, or corrosion on a grounding wire is a physical condition. Working at heights is a physical condition, as are wet floors, and the typical hospital beds (which lead to muscle strains for nurses).

Risk is a measure of human injury, environmental damage or economic loss in terms of both the incident likelihood and the magnitude of the loss or injury. [2] Risk requires an understanding of both the magnitude and the likelihood of an incident occurring. A risk-based decision involves first assessing the risk, and then deciding whether to proceed with the activity, knowing the risk. It requires the establishment of a "risk tolerance".

This presentation discusses a module (a set of slides), with test questions, which has been developed for providing instruction and support for engineering students to understand the concepts of hazard identification, risk assessment and then risk management.

The module will be presented, along with student feedback from the first test usage.

\section{REFERENCES}

[1] 2013 Accreditation Criteria and Procedures, Canadian Engineering Accreditation Board, Engineers Canada, Ottawa, Ontario, 2013.

[2] Guidelines for Chemical Process Quantitative Risk Analysis, Centre for Chemical Process Safety, Wiley, New York, 2000. 